\title{
Influence of Silica Fume on Durability of Cement- Based Materials Exposed to Chlorides
}

\author{
Martina Kovalcikova ${ }^{1}$, Adriana Estokova ${ }^{2}$, \\ ${ }^{1,2}$ Technical University of Košice
}

\begin{abstract}
The deterioration of cement-based materials used for the civil infrastructure has led to the realization that cement-based materials, such as concrete, must be improved in terms of their properties and durability. The use of admixtures, e.g. silica fume, is a relatively convenient way of improving cement-based materials. This paper is focused on the use of silica fume to improve durability of cement-based materials exposed to hydrochloric acid. Effect of hydrochloric acid attack on the silica fume based cement composites and cement composites of ordinary CEM I Portland cement without any additives was investigated during 180 days under model laboratory conditions. The calcium and silicon contents in leachates were evaluated during the experiments using $X$ - ray fluorescence method (XRF). Silica fume based concrete samples were found to have better performance in terms of calcium and silicon ions leaching for all environments except for distilled water environment. The highest concentrations of leached calcium $(619.2 \mathrm{mg} / \mathrm{L})$ and silicon $(1581 \mathrm{mg} / \mathrm{L})$ ions were observed for the sample without silica fume addition placed in the solution of hydrochloric acid.
\end{abstract}

Keywords - Concrete, chloride attack, leaching, silica fume.

\section{INTRODUCTION}

Concrete and cement-based materials are the most widely used building materials globally, finding application in such diverse situations as building of all kinds, civil engineering structures, water supply and drainage infrastructure, agroindustrial infrastructure, transport infrastructure, and so on. Concrete is exposed to many highly aggressive environments due to various chemical and/or biological components. The effect of hydrochloric acid on cement based materials has been studied or reported by various authors [1] - [4].

Hydrochloric acid attacks the cement based material and allows the leaching of calcium. The specimen loses its binding ability and its porosity is increased. There are many different ways in which chloride ions can be introduced to a concrete structure. Chlorides can be introduced to the concrete mix in an admixture or in contaminated aggregates or mix water, or they can diffuse into hardened concrete from external sources such as salt water or deicing salts. When chloride ions are included in a concrete mix, a substantial portion of the chloride ions are combined in solid cement hydration products and do not remain in the pore solution [5].

There are four fundamental modes how chloride ions are transported through concrete: diffusion, capillary absorption, evaporative transport and hydrostatic pressure.

Diffusion is the movement of chloride ions under a concentration gradient. It will occur when the concentration of chlorides on the outside of the concrete member is greater than on the inside. The chloride ions in concrete will naturally migrate from the regions of high concentration (high energy) to the low concentration (low energy) as long as sufficient moisture is present along the path of migration. This process can be modelled mathematical by Fick's First and Second Law of Diffusion. Moreover, it is the principal mechanism that drives chloride ions into the pore structure of concrete [6] - [7].

Fick's First Law describes the flow of an impurity in a substance, showing that the rate of diffusion of the material across a given plane is proportional to the concentration gradient across that plane. It states for chloride diffusion into concrete or for any diffusion process considered in onedimensional situation that:

$$
J=-D_{\text {eff }} \frac{\mathrm{dC}}{\mathrm{dx}}
$$

where $J$ is the rate of diffusion of the chloride ions, $D_{\text {eff }}$ is the effective diffusion coefficient, $C$ is the concentration of chloride ions, and $x$ is a position variable. The minus sign means that mass is flowing in the direction of decreasing concentration. The effective diffusion coefficient considered the effect of the chloride ions movement through a heterogeneous material like the concrete. Hence, the rate of diffusion calculated includes the effect of the concrete porous matrix that contains both solid and liquid components. The equation can be used only when no changes in concentration in time are present [8].

Fick's Second Law is a derivation of the first law to represent the changes of concentration gradient with time. It states that for the effective diffusion coefficient $\left(D_{\text {eff }}\right)$ the rate of change in concentration with time $(t)$ is proportional to the rate at which the concentration gradient changes with distance in a given direction:

$$
\frac{\partial \mathrm{C}}{\partial \mathrm{t}}=D_{e f f} \frac{\partial^{2} \mathrm{C}}{\partial \mathrm{x}^{2}}
$$

If the following boundary conditions are assumed: surface concentration is constant $\left(C_{(\mathrm{x}=0, \mathrm{t}>0)}=C_{0}\right)$, initial concentration in the concrete is zero $\left(C_{(\mathrm{x}>0, \mathrm{t}=0)}=0\right)$ and concentration at an 
infinite point far enough from the surface is zero $\left(C_{(\mathrm{x}=\infty, \mathrm{t}}>0\right)=$ $0)$. The equation can then be reduced to:

$$
\frac{C(x, t)}{C_{0}}=1-\operatorname{erf}\left(\frac{x}{\sqrt{4 \times t \times D_{e f f}}}\right)
$$

where erf is the error function [9].

Capillary absorption occurs when the dry surface of the concrete is exposed to moisture (perhaps containing chlorides). The solution is drawn into the porous matrix of the concrete by capillary suction, much like a sponge. Generally, the shallow depth of chloride ion penetration by capillary action will not reach the reinforcing steel. It will, however, reduce the distance that chloride ions must travel by diffusion [10].

The evaporative transport mechanism, also known as wicking effect, is produced by vapour conduction from a wet side surface to a drier atmosphere. This is a vapour diffusivity process where a retained body of liquid in the pore structure of the concrete evaporates and leaves deposits of chlorides inside. For this mechanism to occur, it is necessary that one of the surfaces be air-exposed.

Another mechanism for chloride ingress is permeation, driven by hydrostatic pressure gradient. A hydrostatic pressure gradient can provide the required force to move liquid containing chlorides ions through the internal concrete matrix. An external hydrostatic pressure can be supplied by a constant wave action or by a retained body of water like bridges, piers, dams, etc. that are exposed to a marine environment [11].

The chloride resistance of concrete is highly dependent on the porosity of concrete in terms of pore size, pore distribution and interconnectivity of the pore system. The porosity of concrete is determined by:

- the type of cement and other mix constituents;

- concrete mix proportions;

- compaction and curing [12].

A pozzolan is a material that contains silica that is able to react with calcium hydroxide. Advantages of using pozzolans in concrete include improved workability of harsh mixes, lower heat of hydration, and improved permeability and durability of hardened concrete. When pozzolans are used in concrete, the rate of early strength gain is often reduced, but over time, the strength of the concrete is improved. However, if the water requirement of a concrete mix is increased by the addition of a pozzolan, an increase in drying shrinkage and creep should be expected. There are many different materials that can function as pozzolans. Some occur naturally, such as volcanic ashes, pumicite, opaline cherts, clays, and shales. Other pozzolans are synthetic, often industrial waste products, such as silica fume (Fig. 1.), fly ash, and quenched boiler slag [13].

Silica fume is an industrial waste that can be used in cement and other building materials and is available at minimum cost.

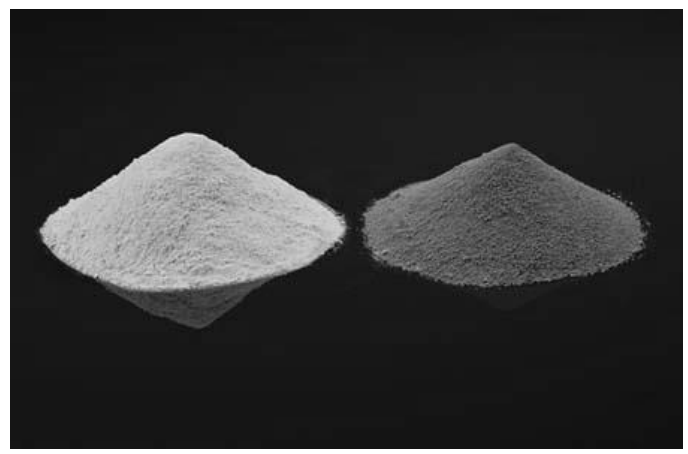

Fig.1. Silica fume.

This by-product of coal fired ferro-silicon alloy industries can be used as a partial replacement for cement and as a supplementary addition to achieve different properties of concrete. Most silica fumes consist of at least $85 \%$ amorphous silicon dioxide [14]. Silica fume is available as a powder, densified powder, or liquid slurry [15]. When silica fume is mixed into concrete, it reacts with excess calcium hydroxide to form calcium silicate hydrate binder, which causes the material to be stronger and less permeable. The small size of silica fume particles allows them to fill in voids in the cement paste and between the paste and the aggregate. As a result, concrete made with silica fume has a less permeable microstructure with fewer gaps or large calcium hydroxide crystals [16].

This paper is focused on the use of silica fume to improve durability of cement-based materials exposed to hydrochloric acid during 180 days under model laboratory conditions.

\section{MATERIALS AND METHODS}

The leaching behavior of calcium and silicon ions from cement composites in laboratory was investigated during 180 days under laboratory model conditions.

\section{A. Concrete Samples}

The concrete samples used in the experiment were prepared using cement CEM I $42.5 \mathrm{~N}$ as the most commonly produced and used cement type.

Two mixtures of concrete (mixture 1 and 2) were used for the preparation of concrete samples for the experiment, using cement CEM I $42.5 \mathrm{~N}$. The composition of these mixtures was prepared considering slightly aggressive chemical environment exposure class XA1 (mixture 1 and 2 with concrete strength class of C 25/30) in accordance with EN 206-1. Quality of concrete, mainly strength and durability, strongly depends on the water amount. Therefore in the EN 206-1, the recommendations in terms of water-cement ratio (w/c) are given for each environmental exposure and strength class. Mix proportion of concrete samples with appropriate w/c ratio for concrete with above mentioned specifications is given in Table 1. 
TABLE I

MIX PROPORTIONS OF TWO DIFFERENT CONCRETE MIXTURES

\begin{tabular}{|c|c|c|}
\hline Mixture & $\mathbf{1}$ & $\mathbf{2}$ \\
\hline Cement & $360 \mathrm{~kg}$ & $360 \mathrm{~kg}$ \\
\hline Water & $170 \mathrm{~L}$ & $200 \mathrm{~L}$ \\
\hline Silica fume & - & $20 \mathrm{~kg}$ \\
\hline Fr. 0/4 mm & $825 \mathrm{~kg}$ & $800 \mathrm{~kg}$ \\
\hline Fr. $4 / 8 \mathrm{~mm}$ & $235 \mathrm{~kg}$ & $235 \mathrm{~kg}$ \\
\hline Fr. $8 / 16 \mathrm{~mm}$ & $740 \mathrm{~kg}$ & $740 \mathrm{~kg}$ \\
\hline Plasticizer & $3.1 \mathrm{~L}$ & $3.1 \mathrm{~L}$ \\
\hline w/c ratio & 0.47 & 0.49 \\
\hline
\end{tabular}
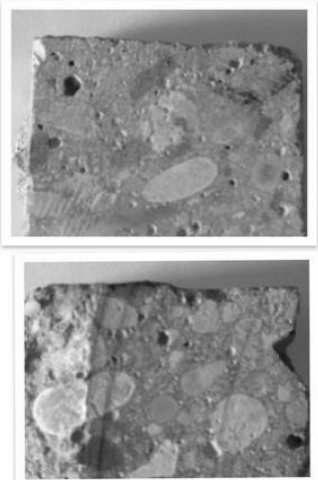
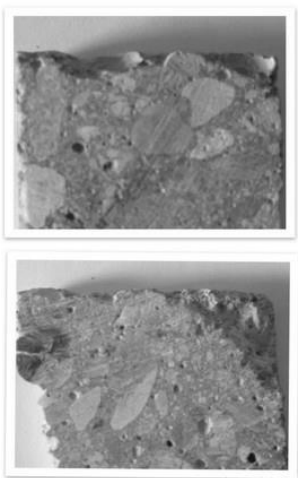

Fig.2. Concrete samples used in experiment.

The prepared concrete prisms of size $100 \times 100 \times 400 \mathrm{~mm}$ were cured for 28 days in water environment and afterwards cut into small prisms with dimensions of $50 \times 50 \times 10 \mathrm{~mm}$ (Fig. 2). The test specimens have been slightly brushed in order to remove polluting particles, cleaned, dried and weighted.

\section{B. Laboratory Experiments}

The concrete samples were exposed to the hydrochloric acid and distilled water as reference medium. The characteristics of concrete samples and media are summarized in Table 2.

The volume ratio of concrete sample to the liquid phase was set to $1: 10$ at the beginning of the experiment. The exposition of concrete samples proceeded during 180 days at laboratory temperature of $23{ }^{\circ} \mathrm{C}$. After each 7 day-immersion period, the change in $\mathrm{pH}$, as well as the dissolved concentration of calcium and silicon were measured in leachates. $\mathrm{pH}$ value of hydrochloric acid solutions was kept on constant level of 5.0.

\section{Analytical Methods}

The chemical composition of both concrete samples and leachates were analyzed before and after the experiments by Xray fluorescence analysis (XRF). SPECTRO iQ II (Ametek, Germany) with silicon drift detector (SDD) with resolution of $145 \mathrm{eV}$ at 10000 pulses was used for the analysis (Fig. 3).
TABLE II

CHARACTERIZATION OF SAMPLES AND MEDIA

\begin{tabular}{|c|c|c|}
\hline Sample & Liquid medium & $\begin{array}{c}\text { Characteristics of } \\
\text { medium }\end{array}$ \\
\hline 1A & $\mathrm{HCl}$ & $\mathrm{pH}=5.06$ \\
\hline 1B & distilled water & $\mathrm{pH}=5.63$ \\
\hline 2A & $\mathrm{HCl}$ & $\mathrm{pH}=5.06$ \\
\hline 2B & distilled water & $\mathrm{pH}=5.63$ \\
\hline
\end{tabular}



Fig.3 Spectrometer SPECTRO iQII.

The primary beam was polarized by Bragg crystal and Highly Ordered Pyrolytic Graphite - HOPG target. The samples were measured during 300 and $180 \mathrm{~s}$ at voltage of $25 \mathrm{kV}$ and $50 \mathrm{kV}$ at current of 0.5 and $1.0 \mathrm{~mA}$ under helium atmosphere by using the standardized method of fundamental parameters for cements or liquids. $\mathrm{pH}$ changes were measured by $\mathrm{pH}$ meter FG2- FiveGo (Mettler-Toledo, Switzerland) illustrated in Fig. 4.

\section{RESULTS}

The percentage of the major components which the concrete samples were consisted of before the experiment is illustrated in Table 3 in oxides form. Leaching trend of measured silicon and calcium ions in the liquid phases of samples during 90 days is illustrated in Table 4 and Table 5.

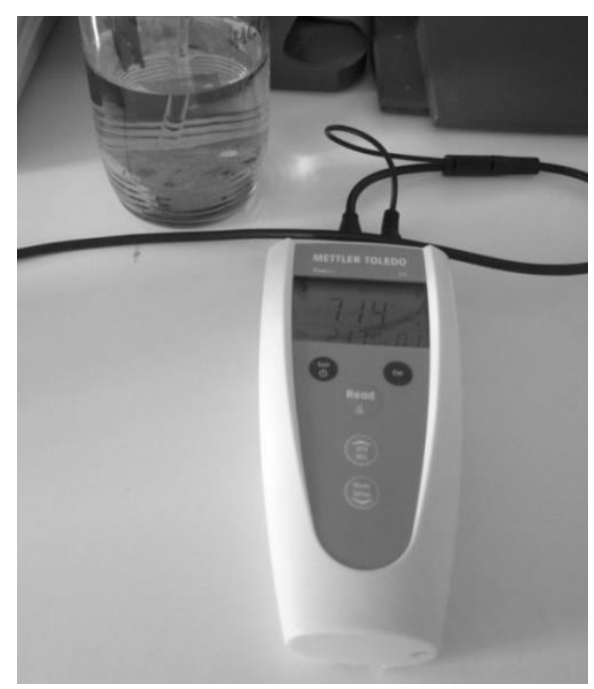

Fig.4. pH meter FG2- FiveGo. 
TABLE III

THE CHEMICAL ANALYSIS OF TESTED CONCRETE SAMPLES

\begin{tabular}{|c|c|c|}
\hline Component & $\begin{array}{c}\mathbf{1} \\
\text { (\% mass) }\end{array}$ & $\begin{array}{c}\text { 2 } \\
\text { (\% mass) }\end{array}$ \\
\hline $\mathrm{Na}_{2} \mathrm{O}$ & 0.11 & 0.11 \\
$\mathrm{MgO}$ & 3.04 & 2.73 \\
$\mathrm{Al}_{2} \mathrm{O}_{3}$ & 5.21 & 5.39 \\
$\mathrm{SiO}_{2}$ & 30.16 & 45.63 \\
$\mathrm{P}_{2} \mathrm{O}_{5}$ & 0.09 & 0.09 \\
$\mathrm{SO}_{3}$ & 2.82 & 2.72 \\
$\mathrm{Cl}$ & 0.02 & 0.02 \\
$\mathrm{~K}_{2} \mathrm{O}$ & 0.77 & 0.79 \\
$\mathrm{CaO}$ & 31.27 & 26.17 \\
$\mathrm{TiO}_{2}$ & 0.27 & 0.26 \\
$\mathrm{MnO}$ & 0.37 & 0.36 \\
$\mathrm{Fe}_{2} \mathrm{O}_{3}$ & 4.04 & 3.75 \\
\hline
\end{tabular}

TABLE IV

THE CONCENTRATIONS OF SI AND CA IONS IN LEACHATES DURING 90 DAYS

\begin{tabular}{|c|cc|cc|}
\hline \multirow{2}{*}{ Days } & \multicolumn{2}{|c|}{ 1A } & \multicolumn{2}{c|}{ 1B } \\
& Si ions & Ca ions & Si ions & Ca ions \\
& {$[\mathrm{mg} / \mathrm{L}]$} & {$[\mathrm{mg} / \mathrm{L}]$} & {$[\mathrm{mg} / \mathrm{L}]$} & {$[\mathrm{mg} / \mathrm{L}]$} \\
\hline 7 & 171.2 & 132.3 & 500.6 & 90.6 \\
14 & 978.1 & 173.3 & 212.4 & 801.3 \\
21 & 234.6 & 157.3 & 1130.0 & 88.8 \\
28 & 1354.0 & 179.4 & 413.3 & 51.6 \\
35 & 787.5 & 195.3 & 593.3 & 43.7 \\
42 & 798.8 & 319.1 & 659.9 & 61.7 \\
49 & 610.0 & 239.9 & 1222.0 & 63.2 \\
56 & 587.9 & 229.8 & 1334.0 & 68.0 \\
63 & 659.0 & 276.9 & 1463.0 & 102.2 \\
70 & 685.5 & 264.5 & 774.3 & 83.9 \\
77 & 521.8 & 259.7 & 457.1 & 1095.0 \\
83 & 1196.0 & 449.4 & 450.0 & 143.8 \\
90 & 583.7 & 347.9 & 677.4 & 337.8 \\
\hline
\end{tabular}

In concrete mixture 1 (without any additives), the maximum of silicon ions concentrations $(1463 \mathrm{mg} / \mathrm{L})$ was measured in leachate of sample 1B immersed in distilled water after 63 days of experiment as it is seen in Table 4.

Similarly, the highest concentrations of leached calcium ions $(1095 \mathrm{mg} / \mathrm{L})$ were observed in leachate of sample 1B (distilled water) after 77 days of experiment (Table 4).

In concrete mixture 2 with addition of silica fume, the highest concentrations of leached silicon ions (1907 mg/L) were observed in leachate of sample $2 \mathrm{~A}$ exposed to hydrochloric acid with $\mathrm{pH}$ of 5.06 after 83 days of exposition (Table 5). The maximum of calcium ions concentration $(358.5 \mathrm{mg} / \mathrm{L})$ dissolved in the distilled water was observed in leachate of sample 2B after 90-day experiments. The concrete sample 2A exposed to hydrochloric acid was found to have better leaching performance of silicon and calcium ions than sample $2 \mathrm{~B}$ after 90 days of exposition.

Comparing the environment of hydrochloric acid to the environment of distilled water - concrete mixture with addition of silica fume is more suitable for more aggressive environment of hydrochloric acid than for the environment of distilled water as it can be seen in Table 5 .

Masses of dissolved ions of silicon and calcium after 180day experiment of concrete samples made from mixture 1 are illustrated in Fig. 5.

The more intensive leaching of both silicon $(1581 \mathrm{mg} / \mathrm{L})$ and calcium $(619.2 \mathrm{mg} / \mathrm{L})$ ions in leachates after 180 days of exposition was observed for concrete sample $1 \mathrm{~A}$ exposed to aggressive environment of hydrochloric acid with $\mathrm{pH}$ of 5.06 as it can be seen in Fig. 5. The lower amounts of silicon (556.6 $\mathrm{mg} / \mathrm{L})$ and calcium $(99 \mathrm{mg} / \mathrm{L})$ ions dissolved were observed as assumed in case of the samples immersed into the distilled water.

Measured concentrations of calcium and silicon ions after 180-day experiment of concrete samples made from mixture 2 are illustrated in Fig. 6.

The higher concentration of silicon ions $(1025 \mathrm{mg} / \mathrm{L})$ was measured in leachate of sample $2 \mathrm{~A}$. The higher concentration of measured calcium ions $(362.3 \mathrm{mg} / \mathrm{L})$ was measured in leachate of sample $2 \mathrm{~B}$. The leached mass of silicon from the sample exposed to hydrochloric acid with $\mathrm{pH}$ of 5.06 was calculated to be 2.13 times higher than from sample exposed to distilled water. On the contrary, dissolved mass of calcium ions was calculated to be 1.74 times higher in case of distilled water as it can be seen in Fig. 6 .

TABLE V

THE CONCENTRATIONS OF SI AND CA IONS IN LEACHATES DURING 90 DAYS

\begin{tabular}{|c|cc|cc|}
\hline \multirow{2}{*}{ Days } & \multicolumn{2}{|c|}{ 2A } & \multicolumn{2}{c|}{ 2B } \\
& Si ions & Ca ions & Si ions & Ca ions \\
& {$[\mathrm{mg} / \mathrm{L}]$} & {$[\mathrm{mg} / \mathrm{L}]$} & {$[\mathrm{mg} / \mathrm{L}]$} & {$[\mathrm{mg} / \mathrm{L}]$} \\
\hline 7 & 955.8 & 68.2 & 335.2 & 180.5 \\
14 & 496.7 & 93.3 & 660.8 & 163.9 \\
21 & 504.6 & 115.8 & 1045.0 & 68.8 \\
28 & 687.2 & 112.2 & 1111.0 & 60.6 \\
35 & 643.9 & 140.4 & 412.8 & 34.9 \\
42 & 601.6 & 150.6 & 401.7 & 52.8 \\
49 & 1072.0 & 206.3 & 657.6 & 41.6 \\
56 & 1510.0 & 176.9 & 1146.0 & 63.9 \\
63 & 1355.0 & 189.8 & 705.2 & 172.1 \\
70 & 641.2 & 182.3 & 718.3 & 77.3 \\
77 & 479.5 & 180.2 & 606.1 & 60.2 \\
83 & 1907.0 & 273.9 & 626.9 & 256.5 \\
90 & 470.7 & 194.9 & 1547.0 & 358.5 \\
\hline
\end{tabular}




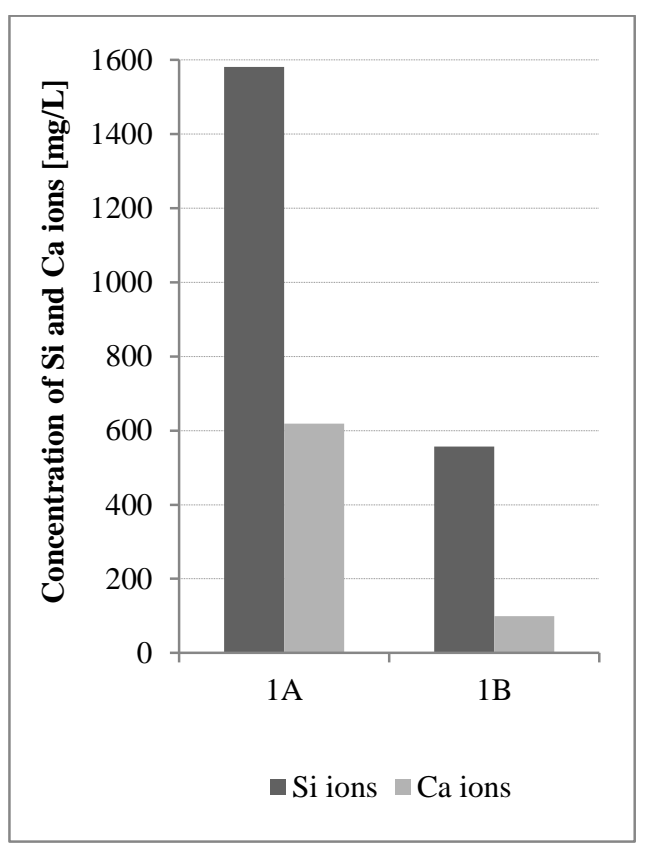

Fig. 5. Dissolved ions of silicon and calcium after 180-day experiment of concrete samples made from mixture 1 .

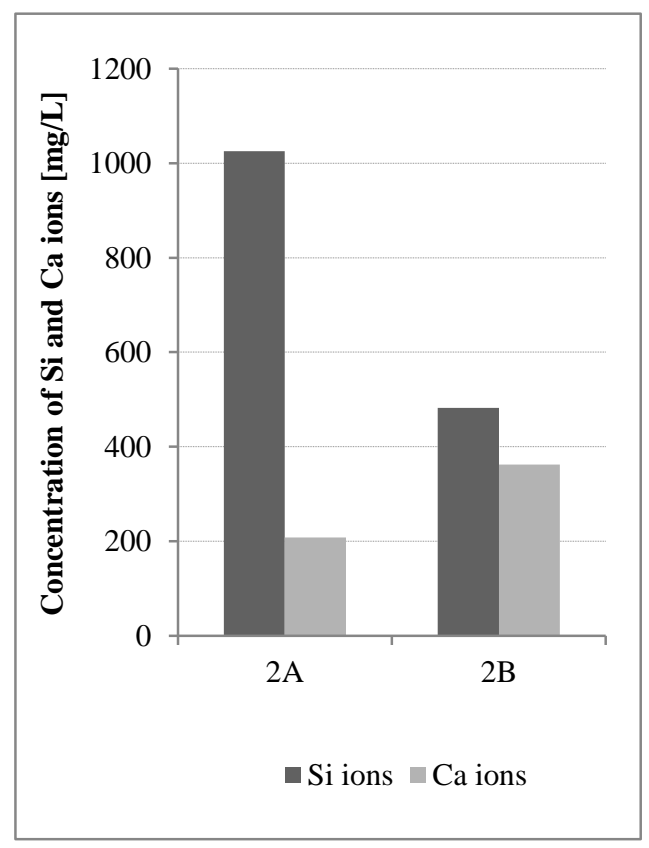

Fig. 6. Dissolved ions of silicon and calcium after 180-day experiment of concrete samples made from mixture 1.

Masses of leached ions of silicon and calcium after 180 day experiment corresponding to $1 \mathrm{~g}$ of concrete sample are illustrated in Fig. 7.

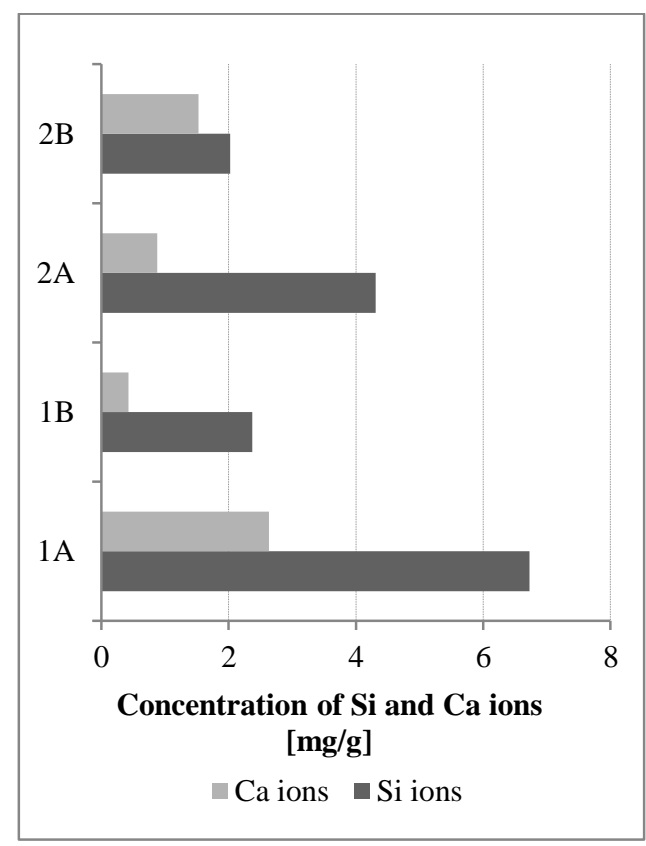

Fig. 7. Dissolved ions of silicon and calcium corresponding to $1 \mathrm{~g}$ of concrete sample.

The most intensive leaching of silicon $(6.728 \mathrm{mg} / \mathrm{g})$ and calcium $(2.635 \mathrm{mg} / \mathrm{g})$ ions calculated to $1 \mathrm{~g}$ of concrete sample after 180 days of exposition were observed for concrete samples $1 \mathrm{~A}$ exposed to hydrochloric acid solution. The lowest amount of leached calcium ions was observed in case of the samples 1B $(0.421 \mathrm{mg} / \mathrm{g}$ of concrete sample) immersed into the distilled water. The minimum of dissolved silicon ions was noticed in leachate of sample 2B $(2.026 \mathrm{mg} / \mathrm{g})$.

\section{CONCLUSION}

The aim of this research was to evaluate the deterioration effect of chloride attack during 180 days under model laboratory conditions. The experimental program was based on two concrete mixtures made with a water-to-binder ratio of 0.47 and 0.49 . An ordinary Portland cement and blended silica fume cement were used to compare the effect of silica fume on leaching of silicon and calcium ions from cement matrix into the solution of hydrochloric acid and distilled water.

It has been shown by several researchers that addition of silica fume to concrete significantly reduces the chloride permeability.

Summarizing the results, the effectiveness of addition of silica fume to concrete mixture in case of aggressive environment of hydrochloric acid was confirmed. The leaching of silicon and calcium ions was 1.562 and 3.011 times lower for concrete sample $2 \mathrm{~A}$ with addition of silica fume compared to the reference sample. 


\section{ACKNOWLEDGEMENTS}

This research has been carried out within the Grants No. 2/0145/15 and 1/0481/13 of the Slovak Grant Agency for Science.

\section{REFERENCES}

[1] D. Israel, D. Macphee and E. Lachowski. "Acid attack on pore-reduced cements." in J. Mater. Sci. Vol. 32, 15, 1997. pp. 4109-4116. http://dx.doi.org/10.1023/A:1018610109429

[2] A. Allahverdi and F. Škvára. "Acidic Corrosion of Hydrated Cement Based Materials, Part 1; Mechanism of the Phenomenon." in CeramicsSilikáty. Vol. 44(3), 2000. pp. 114-120.

[3] L. De Ceukelaire. "The effects of Hydrochloric Acid on Mortar" in Cem. Conc. Res. Vol. 22, 1992. pp. 903-914. http://dx.doi.org/10.1016/0008 8846(92)90114-B

[4] S. Chandra. "Hydrochloric Acid Attack on Cement Mortar - An Analytical Study." in Cem. Conc. Res. Vol. 18(2), 1988. pp. 193-203. http://dx.doi.org/10.1016/0008-8846(88)90004-X

[5] A. Bentur, S. Diamond and N.S. Berke. "Steel Corrosion in Concrete." E and FN Spon, New York, NY, 1997. 201 pp.

[6] K. Tuutti. "Corrosion of steel in concrete." Swedish Cement and Concrete Research Institute, Stockholm. 1982. pp. 469.

[7] K. Stanish and M. Thomas. "The use of bulk diffusion tests to establish time-dependent concrete chloride diffusion coefficients." in Cement and Concrete Research, vol. 33, 2003, no. 1. pp. 55-62.

[8] A. Miles. "Diffusion in Solids and Fick's Laws." 2008. http://www.mrplaceholder.com/papers/fickslaws.pdf(08/03/2014)

[9] H.R. Hamilton III. "Permeability of concrete - comparison of conductivity and diffusion methods." Final Report. Florida, June 2007. pp. 222.

[10] M.D.A. Thomas, S.J. Pantazopoulou and B. Martin-Perez. "Service Life Modelling of Reinforced Concrete Structures Exposed to Chlorides-A Literature Review", prepared for the Ministry of Transportation, Ontario, at the University of Toronto, 1995.

[11] P.K. Mehta. "Durability of Concrete Exposed to Marine Environment - A Fresh Look", Proc,Second Int. Conf. on Concrete in Marine Environment, SP-109, St. Andrews by-the-Sea, Canada, 1988.

[12] S. Mindess and F.J. Young. "Concrete", Prentice-Hall, Inc., Englewood Cliffs, New Jersey, 1981. pp. 194-197.

[13] M.D. Luther. "Silica Fume (Microsilica) Concrete in Bridges in the United States. " in Transportation Research Record, No. 1204, pp. 11-20.

[14] M.R. Sherman, R.L. Carrasquillo and D.W. Fowler. "Field Evaluation of Bridge Corrosion Protection Measures." Report No. FHWA/TX 93+1300-1, Texas Department of Transportation, Austin, Texas, 1993.

[15] N.S. Berke, D.W. Pfeifer and T.G. Weil. "Protection against ChlorideInduced Corrosion." in Concrete International, Vol. 10, No. 12, Dec. 1988. pp. 45-55. 